\title{
Detiding ADCP Data in a Highly Variable Shelf Sea: The Celtic Sea
}

\author{
L. CARrillo* \\ School of Ocean Sciences, University of Wales, Bangor, Bangor, and Proudman Oceanographic Laboratory, \\ Liverpool, United Kingdom
}

A. J. Souza AND A. E. Hill

Proudman Oceanographic Laboratory, Liverpool, United Kingdom

J. Brown ${ }^{+}$AND L. Fernand

Centre for Environment Fisheries and Aquaculture Science, Lowestoft, Suffolk, United Kingdom

J. CANDELA

Centro de Investigacion Cientifica y de Estudios Superiores de Ensenada, Tijuana-Ensenada, Mexico

(Manuscript received 4 November 2003, in final form 3 June 2004)

\begin{abstract}
This paper presents a comparison of two conventional detiding techniques carried out for ship-mounted acoustic Doppler current profiler (ADCP) data collected in the European shelf area of the Celtic Sea during the summer of 1998 . One technique consisted of extracting the vertically averaged tidal currents obtained from a barotropic three-dimensional numerical tidal model. The second technique consisted of fitting the spatiotemporal ADCP data using least squares and polynomial spatial functions. In the least squares technique, the incorporation of zero velocity normal to the coast appears to improve the estimation of the tidal currents near the coast. Quantitative comparisons of the results from both techniques with historical current meter observations are shown. However, both methods showed limitations in accurately representing the tidal currents in the study area. Consequently, an alternative detiding technique is proposed. This technique consists of blending the tidal currents derived from the numerical model with those fitted to the ADCP data from the least squares method. Improved results were obtained using the blending technique. ADCP-derived residual currents were comparable with contemporaneous flows measured using drifting buoys and also with estimates obtained by geostrophic calculations.
\end{abstract}

\section{Introduction}

Over the European continental shelf, tides account for typically $90 \%$ of the variability in measured currents (Howarth and Proctor 1992). These twice-daily excursions of water may exceed $10 \mathrm{~km}$ but play comparatively little role in the longer-term residual flow patterns, which are largely governed by wind forcing and density differences. In order to determine the advection

\footnotetext{
* Current affiliation: El Colegio de la Frontera Sur, Quintana Roo, Mexico.

+ Current affiliation: The British Oceanographic Data Centre, Liverpool, United Kingdom.
}

Corresponding author address: A. J. Souza, Proudman Oceanographic Laboratory, 6 Brownlow St., Liverpool L3 5DA, United Kingdom.

E-mail: ajso@pol.ac.uk of contaminants and fish larvae, it is important to resolve the temporal movement of water at subtidal frequencies and to understand the spatial variability of the flow. While conventional current meter moorings and satellite-tracked drifting buoys are able to provide a degree of understanding, a ship-mounted acoustic Doppler current profiler (ADCP) offers a potentially powerful tool by which to resolve nontidal residual flows at comparatively high resolution over large areas. To be successful, however, it is necessary to remove the energetic tidal signal, a process known as detiding.

In the shelf seas around the British Isles, the detiding of ship-mounted ADCP data has been limited to two approaches. One approach consists of repeated tracks between two points over one or more tidal cycles, effectively building up a series of observations at specific locations along the track (e.g., Simpson et al. 1990; Lwiza et al. 1991; Kasai et al. 1999). A harmonic analysis is then applied to separate the tidal and subtidal 
components of flow. Although this method has been shown to obtain good results, the technique constrains the aerial coverage and is an inefficient use of ship time if the only reason to repeat the survey track is to extract the tides. The other approach is to use a numerical model to predict tidal currents over the region of interest and to subtract this from the ADCP data to produce a spatially more comprehensive view of the residual flow field. Howarth and Proctor (1992), for example, used this technique to study the seasonal cycle in the southern North Sea.

A different approach that allows a description of both tidal and residual currents to be obtained from one survey of an area was originally proposed by Candela et al. (1992). The method is based on obtaining the tidal currents by fitting sinusoidal tidal components with a spatial interpolation using arbitrary functions (polynomials or biharmonic splines) to the ADCP data. This method also allows available nearby measured currents to be combined with the ADCP observations, improving the detiding analysis (Candela et al. 1992). This detiding technique has been successful in other shelf seas (Candela et al. 1992; Münchow et al. 1992; Steger et al. 1998; Wong and Münchow 1995; ValleLevinson and Lwiza 1998; Münchow 2000).

The removal of the tidal signal from ship-mounted ADCP data using the method proposed by Candela et al. (1992) has not been applied in the European shelf area. In this paper, an assessment was made of the suitability of this detiding method for two survey datasets obtained in the Celtic Sea on the northwest European shelf (Fig. 1). In addition, the results from this method are compared with results from a numerical tidal model developed by the Proudman Oceanographic Laboratory (POL). It was observed by Howarth and Proctor (1992) that although models are unbiased for elevations the same is not necessarily true for currents; their nu-

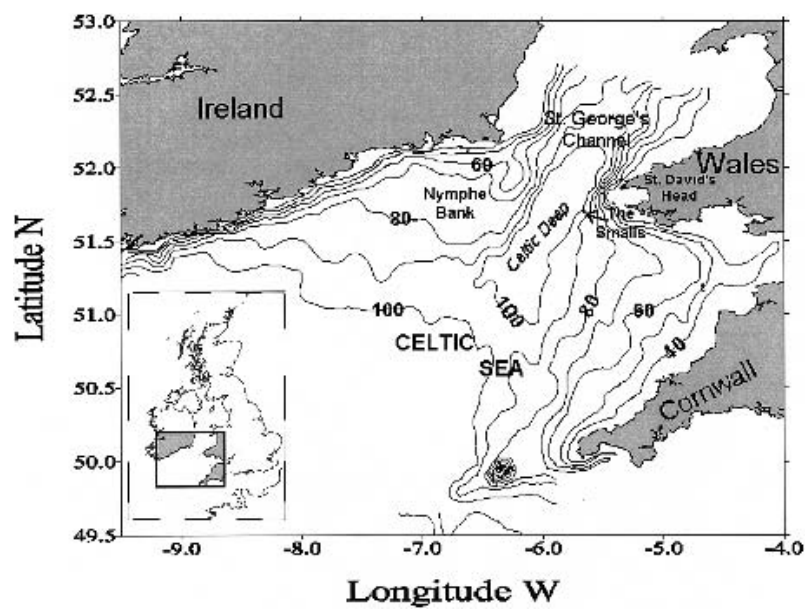

FIG. 1. Study area and its bathymetry. The names of the main bottom topography features and places referred to in the text are indicated. merical-model-predicted velocities were too high and for tidal comparison the spatial variation was more significant than temporal variations. They contended that some corrections to the tidal numerical model results were still needed to obtain more realistic tidal currents. An attempt to correct the phase shift in the twodimensional tidal model results was performed by Howarth and Proctor (1992). They determined the timing differences by regressing subsets of ship-mounted ADCP measurements against the model prediction and selecting the timing that gave the minimum residual variance. An alternative route to correct the numerically modeled tidal currents also using the shipmounted ADCP data is considered here. The technique introduced is to undertake a linear combination of the tidal currents extracted from the observed data using the least squares technique and the tidal currents from the dynamical model. This can be regarded as a simple form of data assimilation known as linear blending. With this idea, the simple alternative detiding technique used here is called the "detiding blending technique."

This paper is organized as follows. Section 2 describes the location, bathymetry, and tidal characteristics of the study area. In section 3 , the measurements used in this work are described. Section 4 presents a brief description of the numerical model and its spatial domain from which the harmonic tidal constituents were obtained. This section also provides the theoretical approach to the detiding technique by least squares using polynomial spatial interpolation. Section 5 deals with the comparison of the tidal results from the conventional detiding techniques of model and least squares. Section 6 introduces an alternative approach to detiding ship-mounted ADCP data, namely the blending technique. Finally, in section 7 , a discussion of the main findings is presented.

\section{Study area}

The Celtic Sea is a semienclosed shelf sea of the northwestern European shelf (Fig. 1), which is surrounded by the historic Celtic lands of Ireland, Wales, Cornwall, and Brittany. This region is connected to the tidally energetic Bristol Channel and southern Irish Sea, the latter through St. George's Channel. The Bristol Channel has depths $<40 \mathrm{~m}$. The southernmost limit of this study area was at $\sim 50^{\circ} \mathrm{N}$, where the Celtic Sea has open communication with the North Atlantic Ocean. In general, the Celtic Sea is a shallow embayment with depth range between 30 and $120 \mathrm{~m}$ (Fig. 1). Its bottom topography is characterized by an elongated basin with depths of $\sim 100-110 \mathrm{~m}$, named the Celtic Deep, that extends from St. George's Channel toward the center of the Celtic Sea along a north-south line inclined $\sim 25^{\circ}$ from the geographic north. In general, the isobaths show a gradual topographic change at the 
eastern side of the shelf, but steeper on the western side (Irish coast), except for the region of the Nymphe Bank. The latter area is an extensive and relatively shallow bank located in the northwest corner of the Celtic Sea with depths ranging from 25 to $75 \mathrm{~m}$. Additionally, there is a shoal area known as the Smalls, distinguished by a series of small, rocky isles. A pronounced, steep seabed slope forms the coastal borders of St. George's Channel, representing the steepest region of the bottom topography of the Celtic Sea.

Tides are an important forcing in this continental shelf sea area. In particular, the semidiurnal tidal constituents $\mathrm{M}_{2}$ and $\mathrm{S}_{2}$ comprise $90 \%$ of the total tidal kinetic energy of currents (Pingree 1980); $\mathrm{M}_{2}$ is the most important tidal constituent, representing $75 \%$ of this total. Cotidal maps of $\mathrm{M}_{2}$ show that the incoming progressive tidal wave travels in a northeastward direction, taking $\sim 2 \mathrm{~h}$ to travel from the shelf break $\left(\sim 49.5^{\circ} \mathrm{N}\right)$ to St. George's Channel. A degenerate amphidromic system lies to the northeast of St. George's Channel. The tidal range varies from about $11 \mathrm{~m}$ at the upper limit of the Bristol Channel to $<1 \mathrm{~m}$ near the amphidromic region. Over the region there is considerable variability in tidal stream amplitude, resulting in different tidal regimes within the Celtic Sea. In the vicinity of Nymphe Bank, current speeds of springs are approximately $0.3 \mathrm{~m} \mathrm{~s}^{-1}$, whereas in St. George's Channel, tidal currents exceed $1 \mathrm{~m} \mathrm{~s}^{-1}$ (e.g., at the Smalls currents are $>1.5 \mathrm{~m} \mathrm{~s}^{-1}$ ). In surrounding areas, such as the English Channel and Bristol Channel, tidal currents are even stronger. In most of the Celtic Sea, the $\mathbf{M}_{2}$ tidal ellipses rotate clockwise, but they become anticlockwise in the northeastern region of the Celtic Sea near the entrance of the Bristol Channel (Robinson 1979). The Celtic Sea is a less restricted area in comparison with the Bristol Channel, Irish Sea, and English Channel, so it exhibits a more circular tidal ellipse, with the minor axis $\sim 20 \%-25 \%$ of the major axis. The ellipse becomes more elongated and almost rectilinear (the ratio of minor to major axes is less than $10 \%$ ) toward laterally constricted areas such as the Bristol Channel, Irish Sea, and English Channel. The principal solar semidiurnal $\left(S_{2}\right)$ appears to be very similar to $M_{2}$, except that $S_{2}$ is only about $33 \%$ of the tidal amplitude of the $\mathrm{M}_{2}$ currents.

\section{Measurements}

The current measurements were obtained in two observational campaigns conducted in the Celtic Sea during the summer of 1998 aboard the R/V Corystes. A ship-mounted RD Instruments broadband $153.5-\mathrm{kHz}$ ADCP with a beam configuration of $30^{\circ}$ concave pattern was used. The first campaign lasted from 13 to 24 July 1998 (hereafter referred to as CORY798). The second campaign lasted from 26 August to 6 September 1998 (hereafter referred to as CORY998). The track length covered during CORY798 (Fig. 2a) was $\approx 990$ $\mathrm{km}$, and was $2500 \mathrm{~km}$ during CORY998 (Fig. 2b). Velocity profiles were obtained over a 1-min average in 2-m-depth bins. The ship's underway velocity was typically $8 \mathrm{kt}\left(4.1 \mathrm{~m} \mathrm{~s}^{-1}\right)$, and the instrument operated in bottom-tracking mode throughout. The navigation system consisted of a Sercel GPS with differential correction with accuracy of $\pm 5 \mathrm{~m}$. Data contaminated by the bottom returns were avoided by eliminating the $15 \%$ of the profile closest to the seabed. The first "good" data bin in the profile was selected at 12-m depth. Data were also discarded during acceleration-deceleration of the ship during frequent station work. A percent good figure was used as a screening criterion, and bin depths with less than $90 \%$ of the return signal were discarded. Here, the calibration procedure was applied as suggested by Joyce (1989). Before either of the detiding
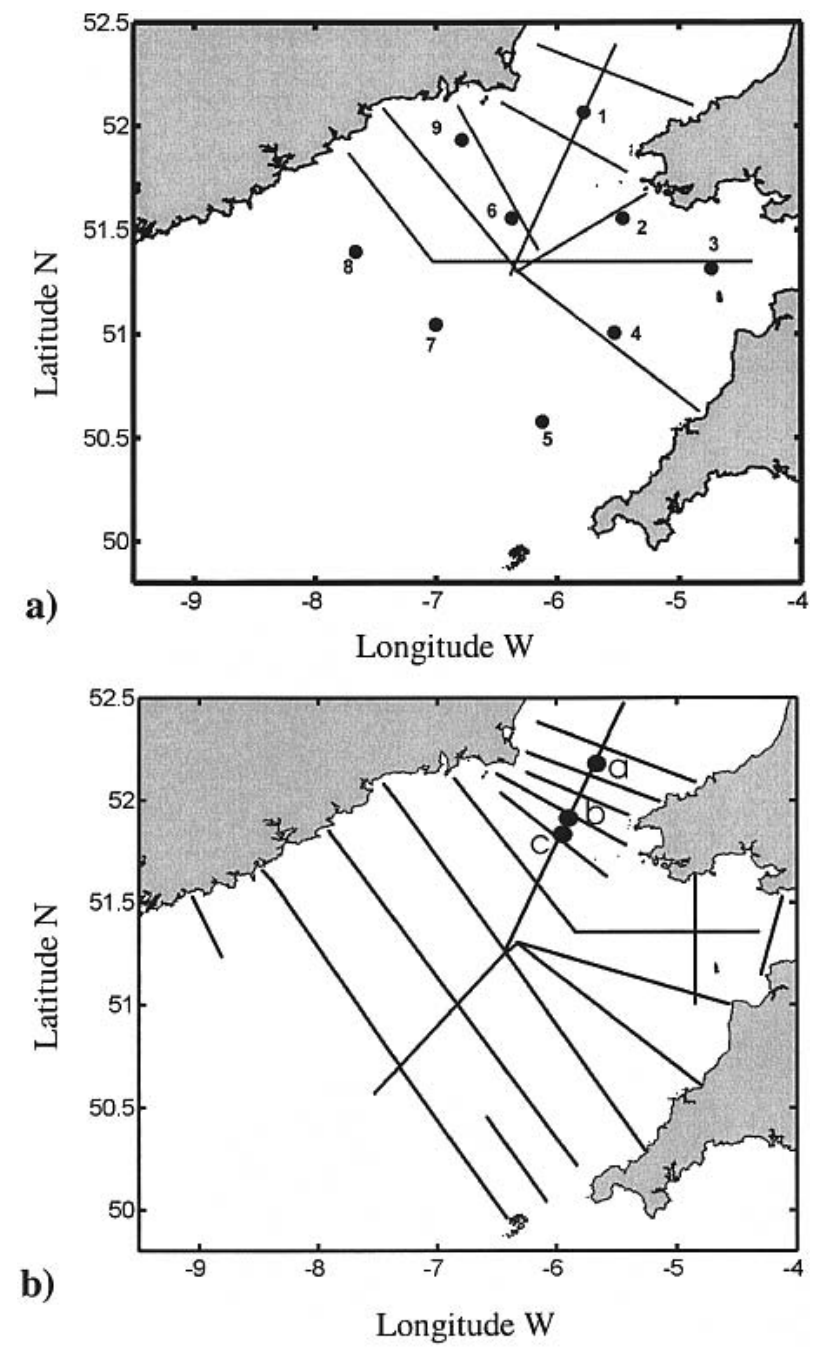

FIG. 2. ADCP cross sections (a) during the CORY798 campaign and current meter locations selected from the BODC database, and (b) during the CORY998 campaign. Location of vertical structure sites a, b, and c used in Fig. 8. 
techniques (least squares or numerical model) was applied, it was decided to reduce further the noise level remaining in the 2-min-averaged ADCP profiles. Consequently, 10-min averages of profiles were applied.

\section{Detiding techniques}

\section{a. The numerical tidal model}

The numerical model, developed at POL by Davies and Jones (1992), was used to provide the harmonic constituents to detide the ship-mounted ADCP data. The model is barotropic and three-dimensional, covering the Celtic Sea and Irish Sea regions based upon a regular finite-difference grid, with horizontal spatial resolution of $\sim 7-\mathrm{km}$ grid size (Davies and Jones 1992). These simulated five of the major tidal constituents for the Celtic Sea, namely, $\mathrm{O}_{1}, \mathrm{~K}_{1}, \mathrm{~N}_{2}, \mathrm{M}_{2}$, and $\mathrm{S}_{2}$. Cotidal charts were in good agreement with observations; however, the same was not true for the predicted tidal currents. In general, tidal currents were overestimated by the model of Davies and Jones (1992). On average, the major axis of the current ellipse for the semidiurnal constituents, $\mathrm{M}_{2}$ and $\mathrm{S}_{2}$, can be up to $0.05 \mathrm{~m} \mathrm{~s}^{-1}$ overpredicted by the model, with phases agreeing to within $5^{\circ}$. In the case of $\mathrm{M}_{2}$, the modeled $u$ component (eastwest) of velocity in the area around St. George's Channel was smaller than observed. The magnitude of the tidal currents for the semidiurnal tidal constituent $\mathrm{N}_{2}$ and the diurnals $\mathrm{K}_{1}$ and $\mathrm{O}_{1}$ were slightly overpredicted by the model. In the case of the diurnal constituents, the tidal ellipse orientation was reproduced with an accuracy of only $10^{\circ}-20^{\circ}$; this difference in orientation is perhaps due to local effects. Because the model is barotropic and is used in an area where stratification is present, errors in the tidal characteristics might arise due to the lack of baroclinic effects, although in this area internal tides and waves are generally not present.

\section{b. Least squares and polynomial spatial interpolation}

In the case of the detiding method, using least squares and polynomial spatial interpolation, we followed the Candela et al. (1992) formulation. They suggested that tidal spatial variability can be included in the harmonic representation of the currents by allowing the constant coefficients to be functions of horizontal spatial coordinates $x$ and $y$. A detailed description of this method can be found elsewhere (Candela et al. 1992; Münchow et al. 1992; Foreman and Freeland 1991; Steger et al. 1998). If the normal modes of the tidal wave in a particular shelf are unknown, arbitrary interpolation functions are suggested. The simplest interpolating functions are polynomials in powers of $x$ and $y$. The tidal constituents of $\mathrm{M}_{2}$ and $\mathrm{S}_{2}$ are considered here, since these semidiurnal frequencies account for $90 \%$ of the total tidal signal in the Celtic Sea. One of the advantages of this detiding method is that ADCP survey data from different cruises in the study area can be used simultaneously to improve the results (Candela et al. 1992). Thus, a longer record was constructed using the ADCP data from both cruises, CORY798 and CORY998. In doing this, we are assuming that tides are stationary over the period of the observations. This assumption is supported by the results of the harmonics analyses of current meter observations from two RD Instruments 306.2-kHz workhorse ADCPs deployed on the seabed during the period of the two cruises in the Celtic Sea (Brown et al. 2003).

It is important to consider that the worst predictions using the polynomial functions are to be expected near the edges of the domain of data coverage (such as the coastal zone), which represents the most serious drawback of this technique. Here, a modified version of the Candela et al. (1992) technique was used that takes into account the presence of coastal boundaries by introducing a zero normal component of the current along a closed boundary (i.e., along the coast) in different locations along the coast (Fig. 3a). It basically consisted of adding equations of zero normal velocity at solid boundaries to the system of equations. Only 23 locations were selected along the coast. Although a larger number of coastal points could be added, care was taken not to overload the equation system, since adding too many coastal zero velocity points would tend to diminish the magnitude of the fitted current field. These equations of zero normal velocity were estimated for a whole tidal cycle (in the case of the Celtic Sea it was $12 \mathrm{~h}$ ). The addition of the boundary conditions improved the orientation of the tidal currents near the coast (an example of this is shown in Fig. 3c); without boundary conditions, tidal currents were toward the coast (Fig. 3b). Away from the boundaries the predicted tidal currents did not change. However, tidal current orientation did not change or improve around the intricate coastalline of St. David's Head (not shown), where rapid changes in phase and in amplitude can be observed.

Additionally, the procedure to obtain the best fit was based on some trial experimentation that involved varying the degree of the polynomial functions. Significant reduction of the root-mean-square (rms) error was observed by increasing the degree of the polynomial for $\mathrm{M}_{2}$ rather than for $\mathrm{S}_{2}$. Moreover, experiments showed that by keeping the polynomial degree for $\mathrm{M}_{2}$ at fourth and increasing the one for $\mathrm{S}_{2}$ from first degree to fourth degree, the rms only decreased by less than 0.01 units. Thus the best fit for the whole study area can be expected by using first degree for $\mathrm{S}_{2}$ and fourth degree for $\mathrm{M}_{2}$ with a maximum rms of \pm 0.07 .

\section{Comparison of the tidal results from the detiding methods}

Using the tidal harmonics for $\mathrm{M}_{2}, \mathrm{~S}_{2}, \mathrm{~N}_{2}, \mathrm{O}_{1}$, and $\mathrm{K}_{1}$ from the numerical model, a program was run to cal- 
a)
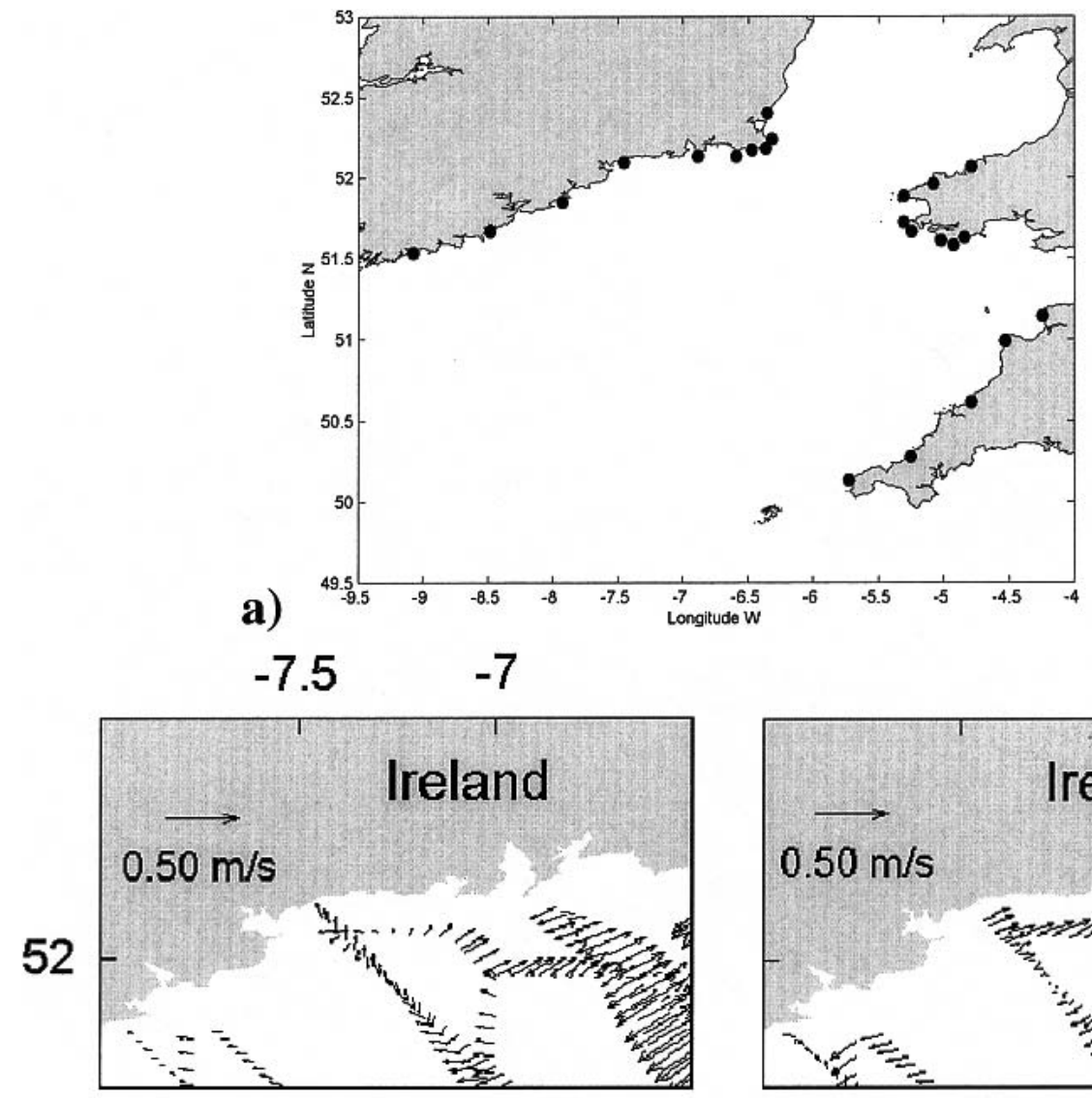

b)

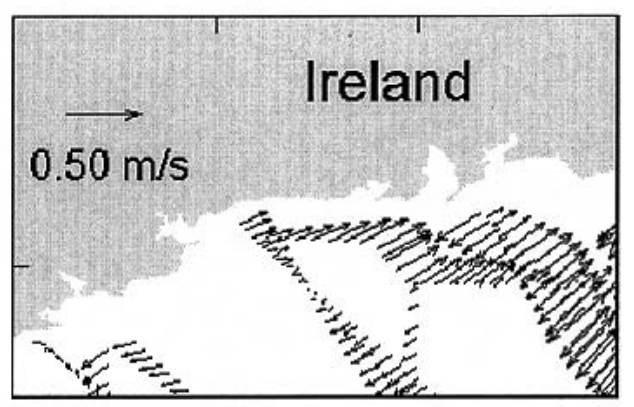

c)

FIG. 3. (a) Selected locations for the boundary condition of zero velocity normal to the coast. (b) Tidal current estimations without boundary conditions in the Irish coast. (c) Tidal current estimations using boundary conditions in the Irish coast.

culate the tidal currents at the times/positions at which ADCP profiles were measured. At each given position, amplitudes and phases for each constituent were determined by bilinear interpolation from those at the nearest grid points. In the case of the least squares technique, the tidal currents were obtained as explained in section $4 \mathrm{~b}$. Figure 4 shows the time series of $u$ and $v$ components of depth-averaged velocity measured with the ship-mounted ADCP and the predicted tidal currents derived using both the numerical model and the least squares fitting. As was expected, the observed velocities showed a strong tidal signal (Fig. 4). The explained variance for the $u$ component ( $v$ component) accounted for $86 \%(88 \%)$ with the numerical model and $82 \%(89 \%)$ with the least squares method. The tidal predictions from both methods were of approximately the same order (Fig. 4).

\section{Tidal ellipses}

We concentrated on $\mathrm{M}_{2}$ for the comparisons because it is the most energetic tidal constituent, and $\mathrm{S}_{2}$ showed a similar behavior. The spatial tidal current ellipses for $\mathrm{M}_{2}$ from both the numerical model (Fig. 5a) and the least squares method (Fig. 5b) approximately showed the same spatial variability of the tidal currents in the area. Both detiding methods closely agreed in the orientation of the tidal ellipses. In general, the methods differed in their prediction of the size of the semi-major axis with a mean of $0.04 \mathrm{~m} \mathrm{~s}^{-1}$. Differences in the semiminor axis were $0.08 \mathrm{~m} \mathrm{~s}^{-1}$ on average. Model and least squares methods differed in phase with a mean value of $30^{\circ}(\sim 1 \mathrm{~h})$, but major phase differences (up to $70^{\circ}$ ) were observed near the open southwestern boundary. In St. George's Channel, $\mathrm{M}_{2}$ tidal currents were rectilinear and the tidal ellipse was oriented along the channel (northeast-southwest). Also, in both methods, tidal ellipses became smaller and more circular near the entrance of the Bristol Channel. In the northern entrance of this channel, tidal ellipses were nearly northwest-southeast orientated, becoming more northeastsouthwest orientated toward the southern entrance. Both methods displayed a tendency for rectilinear tidal ellipses in the remainder of the Celtic Sea. 

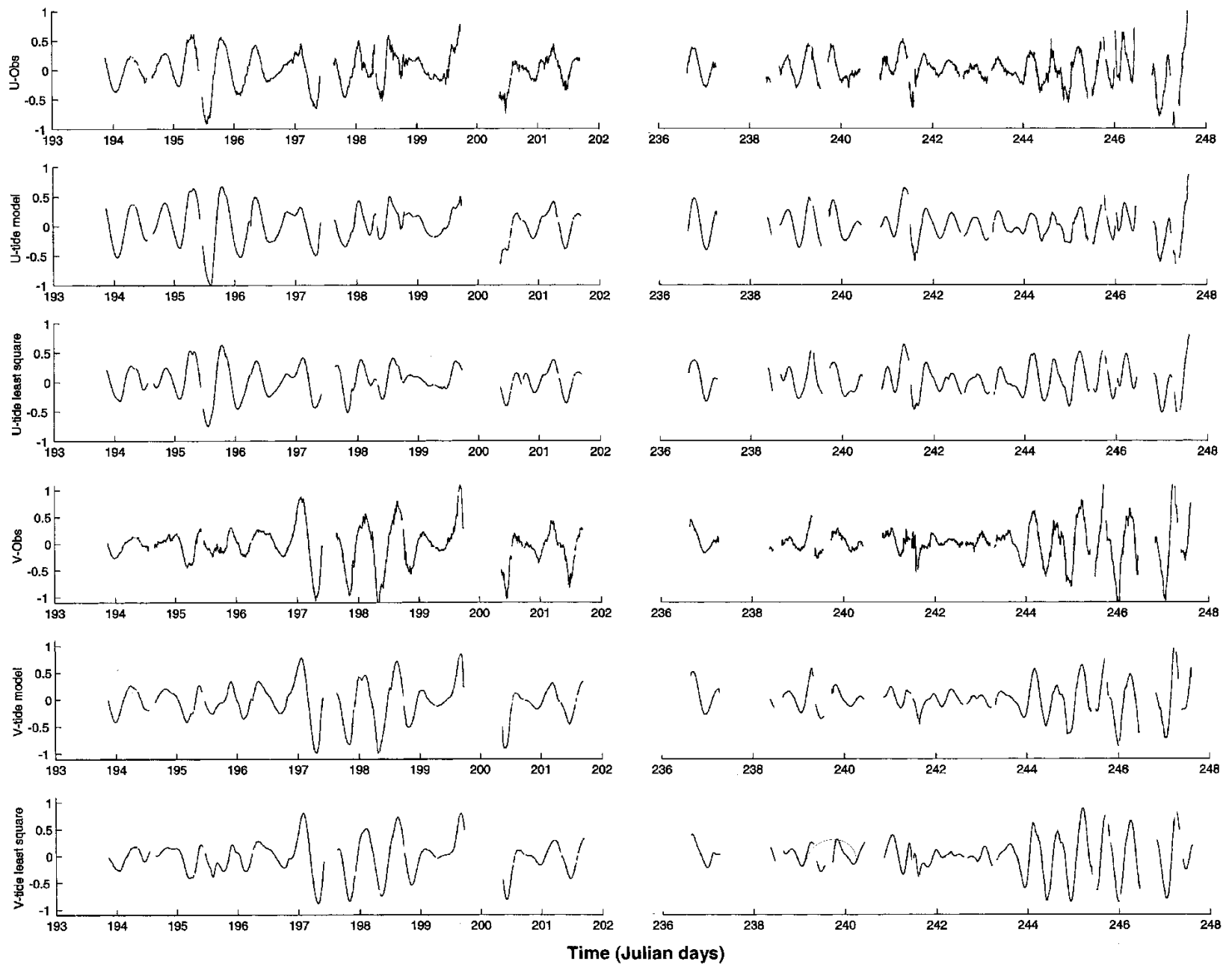

FIG. 4. Time series plots of the east-west $u$ and north-south $v$ velocity components for the ship-mounted ADCP observations, tidal model prediction, and tidal from least squares approach.

In order to compare the tidal predictions with observations, available tidal information extracted from current meter records from the data bank of the British Oceanographic Data Centre (BODC) were used. Nine locations representing different regions of the study area were selected (see Fig. 2a for locations). Four tidal ellipse parameters (semimajor and semiminor axes, orientation and phase of the tidal ellipse) were used in this comparison. Table 1 shows the values of the differences between the current meter measurements and the estimated currents obtained using both detiding methods. Figure 6 shows the tidal ellipses measured by current meters for $\mathrm{M}_{2}$ at the nine selected locations (Fig. 2a) together with the predicted ellipses using the numerical model and the least squares method. In the case of $\mathrm{M}_{2}$, both methods were equally good or bad at predicting currents in areas 1,2, and 3 (Fig. 6 and Table 1). The predicted ellipse orientation was particularly good in St. George's Channel (location 1) for both methods. However, some areas were better predicted with the least squares method, such as areas 5 and 6 , while other areas were better predicted by the model (e.g., areas 4 and 8$)$. The worst-predicted area with the least squares was 9 (near the Irish coast), where the semimajor axis was overestimated by a factor of 3 times the model error (see Fig. 6c and Table 1). The tidal ellipse parameters worst estimated by the least squares method were the semiminor axis (e.g., up to $0.15 \mathrm{~m} \mathrm{~s}^{-1}$ overestimated in location 4 ) and phase (differed by up to $40^{\circ}$ ) (Table 1).

Even when the least squares method is a numericalstatistical approximation to a tidal field captured with a nearly synoptic one-realization survey area, it performed reasonably well for $\mathrm{M}_{2}$. Despite the discrepancies between the least squares tidal ellipse results and the current meter measurements, the total estimated tidal signal $\left(\mathrm{M}_{2}\right.$ plus $\left.\mathrm{S}_{2}\right)$ from this method was not significantly different from the numerical model results (see Fig. 4). On the other hand, current meter data originated from measurements representing discrete 

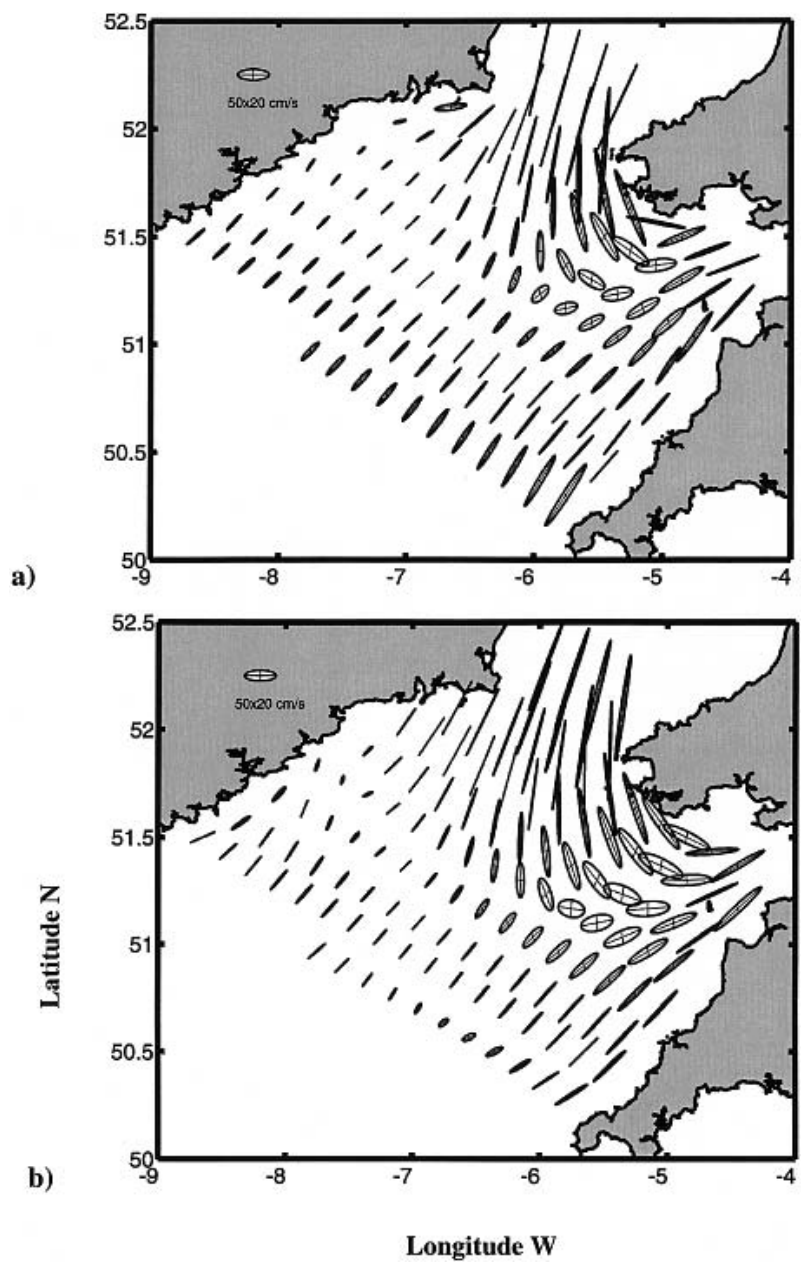

FIG. 5. Tidal ellipse maps for $\mathrm{M}_{2}$ estimated from (a) the numerical model and (b) the least squares technique. Scale appears in the top-left corner.

points in a region with considerable spatial tidal gradients. Consequently, there may be errors in the comparisons with the tidal field estimated from the numerical model and the least squares method. Even though the best estimate of the tidal field was obtained with the numerical model, some errors could still be present. For example, a closer inspection between the ADCP data and the numerical tidal model results showed a phase shift of up to 1-2 h, depending on the area. However, in the comparison with the current meters, the difference was as much as $40 \mathrm{~min}$ (see value in location 6 in Table 1). It is important to consider that the current meters used in this comparison were also used to validate the numerical model (Davies and Jones 1992). Therefore, it is to be expected that the tidal model results performed better close to the current meter locations. Tuning in the numerical tidal model results is still needed in order to obtain a more reliable detiding of the ship-mounted $\mathrm{ADCP}$ data in this region.

\section{A combined detiding approach: Blending technique}

In the preceding section, it was seen that both methods were able to predict reasonably well the main tidal signals in the Celtic Sea and that the numerical model performed slightly better. However, a closer inspection, comparing the time series of the ADCP data and the tidal signal obtained from the numerical model, shows that there were some areas where the numerical model clearly needs tuning. Therefore, in seeking to obtain the subtidal signal from the ADCP data, both methods are likely to fail to solve the spatial variation of tides sufficiently to satisfactorily be able to subtract the tidal fields. Some correction in both methods is still needed. Improvements in the tidal predictions could be obtained with a better spatial resolution (in the case of the numerical model) or with a more dynamical spatial interpolation scheme (in the case of the least squares technique). However, in an attempt to find improvement in reducing the tidal frequency energy from the ADCP data, an alternative technique was adopted.

As established for data assimilation, the combination of observational data with a dynamical approach (model) for the system under observation makes possible more efficient, accurate, and realistic estimation, which might not otherwise be feasible (Robinson et al. 1998). Thus, it is worth considering the possibility that a better estimation of the tidal currents might be obtained by combining the tidal information extracted from the least squares method and using this to correct the tidal results from the numerical model. Moreover, combining or melding the results of a dynamical model with observations usually does not degrade the reliable information of the observational data but rather enhances that information content by reducing the noise (Robinson et al. 1998). There are several melding schemes in data assimilation; however, a linear combination of the observation data and dynamical model is usually chosen. This is known as linear melding or blending (Lermusiaux 1997). However, the aim here is not to perform a data assimilation analysis as such but to use the basic approach as the basis for combining data and model output. Assuming that estimations of the tidal currents from the least squares approach and from the numerical model are unbiased and independent estimates of the true tidal currents, then the linear combination of these two independent tidal current approaches is possible. The detiding blending technique consists of a simple weighted average of the numerical model results with those from least squares method. Thus, it is assumed that at all points the tidal blending estimate is a scalar combination of the tidal currents from the model and from the data values (i.e., least squares technique) in the form

$$
\left(\hat{T}_{k}\right)_{b}=\frac{W_{1} D_{k}+W_{2} \hat{M}_{k}}{W_{1}+W_{2}},
$$


TABLE 1. Tidal ellipses parameters for $\mathrm{M}_{2}$ : semimajor axis, semiminor axis, orientation, and phase at nine locations in the Celtic Sea Location and instrument depths are shown. For each parameter column, current meters (first column), the numerical model (second column), and least squares method (third column).

\begin{tabular}{|c|c|c|c|c|c|c|c|c|c|c|c|c|c|c|}
\hline \multirow{2}{*}{$\frac{\text { Location }}{1}$} & \multirow{2}{*}{$\begin{array}{c}\begin{array}{c}\text { Location } \\
\text { depth } \\
(\mathrm{m})\end{array} \\
91\end{array}$} & \multirow{2}{*}{$\begin{array}{c}\text { Instrument } \\
\text { depth } \\
(\mathrm{m})\end{array}$} & \multicolumn{3}{|c|}{$\begin{array}{l}\text { Semimajor axis } \\
\qquad\left(\mathrm{m} \mathrm{s}^{-1}\right)\end{array}$} & \multicolumn{3}{|c|}{$\begin{array}{l}\text { Semiminor axis } \\
\qquad\left(\mathrm{m} \mathrm{s}^{-1}\right)\end{array}$} & \multicolumn{3}{|c|}{ Orientation $\left(^{\circ}\right)$} & \multicolumn{3}{|c|}{ Phase $\left(^{\circ}\right)$} \\
\hline & & & 0.99 & 0.98 & 1.08 & 0.00 & 0.014 & -0.041 & 62.92 & 64.13 & 65.62 & 41.00 & 33.10 & 45.60 \\
\hline 2 & 71 & 41 & 0.60 & 0.69 & 0.71 & 0.22 & 0.235 & 0.190 & 128.32 & 125.67 & 111.36 & 28.14 & 38.63 & 42.26 \\
\hline 3 & 60 & 35 & 0.59 & 0.75 & 0.75 & 0.16 & 0.105 & 0.131 & 8.66 & 18.68 & 2.83 & -97.64 & -91.51 & -98.02 \\
\hline 4 & 83 & 55 & 0.39 & 0.42 & 0.46 & 0.15 & 0.159 & 0.279 & 22.66 & 21.90 & 12.22 & -77.06 & -84.21 & -82.05 \\
\hline 5 & 90 & 41 & 0.40 & 0.48 & 0.37 & -0.02 & -0.074 & -0.069 & 32.86 & 39.10 & 35.25 & -81.47 & -88.43 & -48.52 \\
\hline 6 & 80 & 70 & 0.39 & 0.34 & 0.40 & 0.07 & 0.082 & 0.081 & 66.36 & 57.89 & 62.95 & 18.47 & -1.89 & 24.14 \\
\hline 7 & 91 & 73 & 0.26 & 0.33 & 0.20 & 0.00 & -0.061 & 0.036 & 29.47 & 30.58 & 34.79 & -62.52 & -72.33 & -59.58 \\
\hline 8 & 88 & 41 & 0.22 & 0.25 & 0.13 & -0.04 & -0.054 & -0.005 & 24.96 & 28.93 & 22.79 & -66.00 & -71.09 & -103.96 \\
\hline 9 & 62 & 40 & 0.23 & 0.34 & 0.57 & -0.05 & -0.059 & -0.024 & 15.54 & 20.52 & 37.81 & 27.25 & 13.17 & 33.38 \\
\hline
\end{tabular}

where $\left(\hat{T}_{k}\right)_{b}$ is the blending estimate of the tidal current at the $k$ th data point, $D_{k}$ is the estimated tidal current from the least squares technique at the $k$ th data point, $\hat{M}_{k}$ is the estimated tidal current from the numerical model at the $k$ th data point, and $W_{1}$ and $W_{2}$ are the weight of the average for $D$ and $M$, respectively.

The assigned values for $W_{1}$ and $W_{2}$ were 0.9 and 1.0, respectively; $W_{2}$ was given this value assuming that $100 \%$ of the tidal variability is due to the five constituents $\mathrm{M}_{2}, \mathrm{~S}_{2}, \mathrm{~K}_{1}, \mathrm{O}_{1}$, and $\mathrm{N}_{2}$. The $W_{1}$ value was assigned by considering that for $D$ only $\mathrm{M}_{2}$ and $\mathrm{S}_{2}$ semidiurnal constituents were calculated, which account for $90 \%$ of the total tidal variability. For illustrative purposes, Fig. 7 shows an example of observations (raw data), the tidal current approximation from the two conventional detiding techniques of numerical model and least squares interpolation and the blending technique. It can be observed that the blending technique acts as a correction procedure for the model-data misfit, which implies a better estimation of the subtidal currents.

\section{a. Vertical structure}

Up to now, we have concentrated on the twodimensional detiding of the ADCP data, in particular, in the horizontal field using depth-averaged velocities, as these were the only data available to us, from Davies and Jones (1992). A complete three-dimensional picture of the residual field can only be achieved by applying detiding to the vertical velocity structure. Extending the blending detiding procedure to the vertical is not straightforward.

In the case of the model, the tidal current profile was derived from a theoretical analytical profile proposed by Prandle (1982) based on boundary layer theory. The vertical structure of the tidal currents in shallow seas is influenced by seabed friction, which reduces the tidal current amplitude near the boundary layer. Thus, a re-
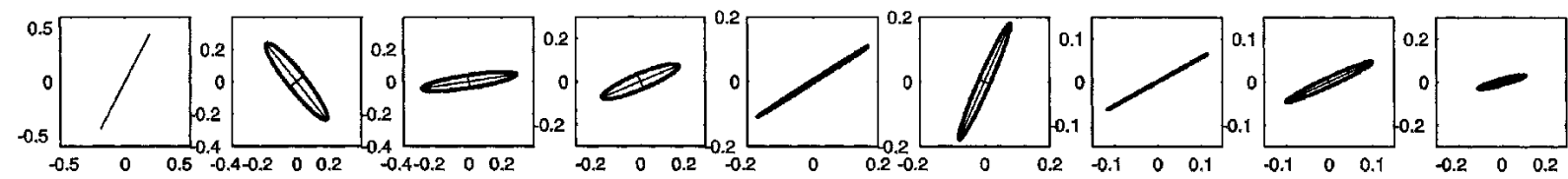

a)
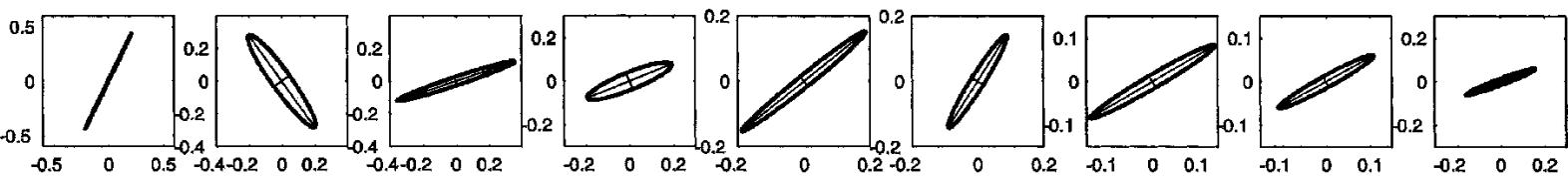

b)
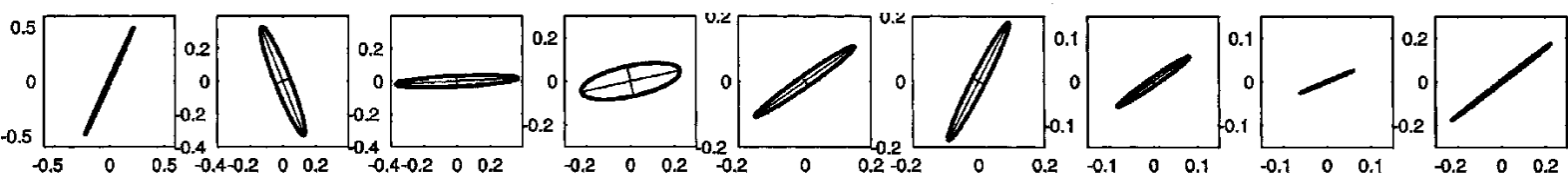

1

3

4

5

6

7

8

9

FIG. 6. Comparison of $\mathrm{M}_{2}$ tidal ellipses obtained from current meters from (a) the selected locations, (b) the tidal ellipses predicted with the numerical model, and (c) least squares method. From left to right, locations 1-9. 

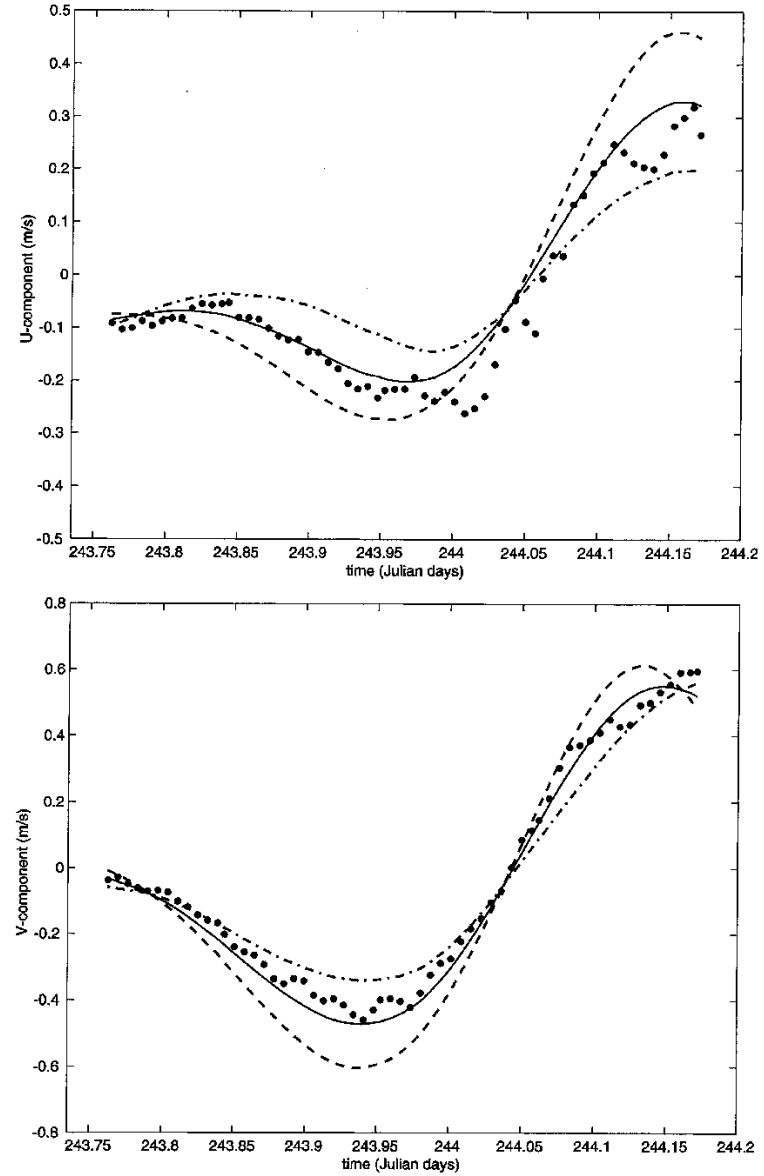

FIG. 7. Comparison of current tidal predictions from different approaches. (top) East-west $u$ and (bottom) north-south $v$ tidal velocity components. Dots represent the observed velocities from ship-mounted ADCP, the dotted-dashed line is tidal current from the numerical model, the broken line is the tidal current estimation from least squares method, and the solid line shows the tidal prediction with the blending technique.

tardation of the flow toward the bottom of the profile is produced; that is, a phase difference exists between the surface tidal current and the near bottom tidal current. Prandle (1982) proposed a barotropic vertical structure of tidal currents that can be represented as

$$
U(z)=\left\{\frac{e^{\frac{z}{\delta}}+e^{-\left(\frac{z}{\delta}-2 y\right)}}{T}+Q\right\} \bar{U},
$$

where

$$
\begin{aligned}
T & =\left(1-e^{2 y}\right)\left\{j-\frac{1}{y}-1\right\}-2 e^{2 y}, \\
Q & =\frac{j\left(1-e^{2 y}\right)-1-e^{2 y}}{T} \\
j & =\frac{3 \pi N_{z}}{8 \delta k|\bar{U}|}
\end{aligned}
$$

$$
\begin{aligned}
& y=\frac{D}{\delta}, \quad \text { and } \\
& \delta=\left(\frac{N_{z}}{i \omega}\right)^{1 / 2},
\end{aligned}
$$

where $i=\sqrt{-1},|\bar{U}|$ is the depth average velocity amplitude, $N_{z}$ is the eddy viscosity, $\omega$ is the tidal frequency, $f$ is the Coriolis parameter, and $k$ is the bottom drag coefficient. Thus, the velocity profile is a function of the variables $j$ and $y$. The modulus of $y$ can be interpreted as a depth parameter converted to dimensionless form by Ekman scaling (Prandle 1982). The modulus of $j$ reflects the effect of the bottom stress through the bed stress coefficient $k$ and the velocity $\bar{U}$.

To avoid adding complexity to the least squares detiding technique, the vertical structure of the tidal currents from the ship-mounted ADCP consisted of the application of the least squares approximation to each depth cell of the dataset. In order to see whether the fitted profiles were similar to those expected, it is useful to compare the two tidal current profile approaches (model and least squares) with the observed profile from the ADCP. Figure 8 shows examples of the vertical structure of the measured velocity (observed profile from ADCP data), and the theoretical and numerical tidal profiles. Both methods tended to present a broadly similar profile shape with some under- and subestimations of the magnitude of the tidal current because of the simplicity of the methods to approach the real tidal profile, which contents tidal and subtidal signals. The vertical structure of the subtidal currents from the ship-mounted ADCP data was obtained by blending the simplified analytical tidal profile for the model detiding technique and the numerical approach from the least squares detiding technique, as explained before. The linear combination is expected to reduce the noise from each method and to improve the results. The performance of the detiding blending technique was tested by comparing the nontidal residuals obtained from this detiding technique with other current measurements coming from drifters and with theoretically expected density-driven currents derived from geostrophic calculations.

\section{b. Validation of $A D C P$ subtidal velocities from the blending method}

The purpose here is to compare the subtidal currents derived from the detiding blending technique applied to the ship-mounted ADCP data with an available contemporaneous set of observed velocities. Drifters were released during the first cruise, CORY798, and some of them were still operating during the second cruise, CORY998. These residual velocities were obtained from 23 satellite-tracked drifters released in the study area and centered at 30-m depth. A map of the quasiEulerian circulation was constructed from the filtered 


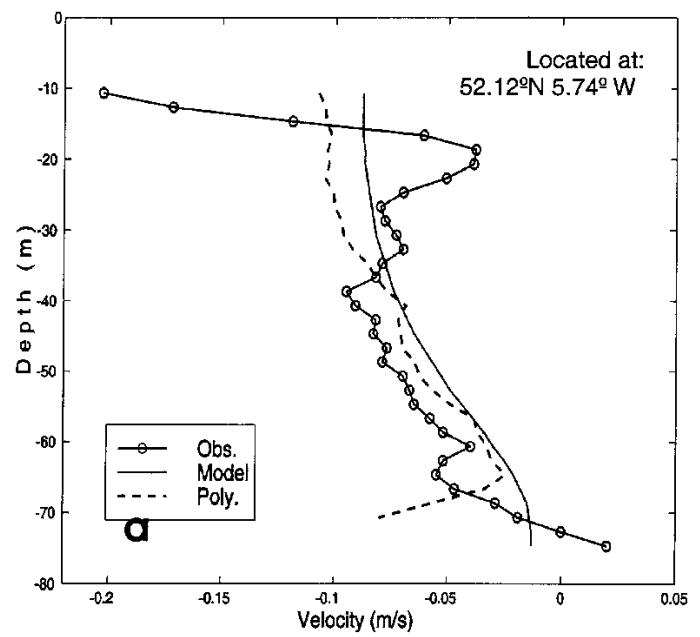

a)
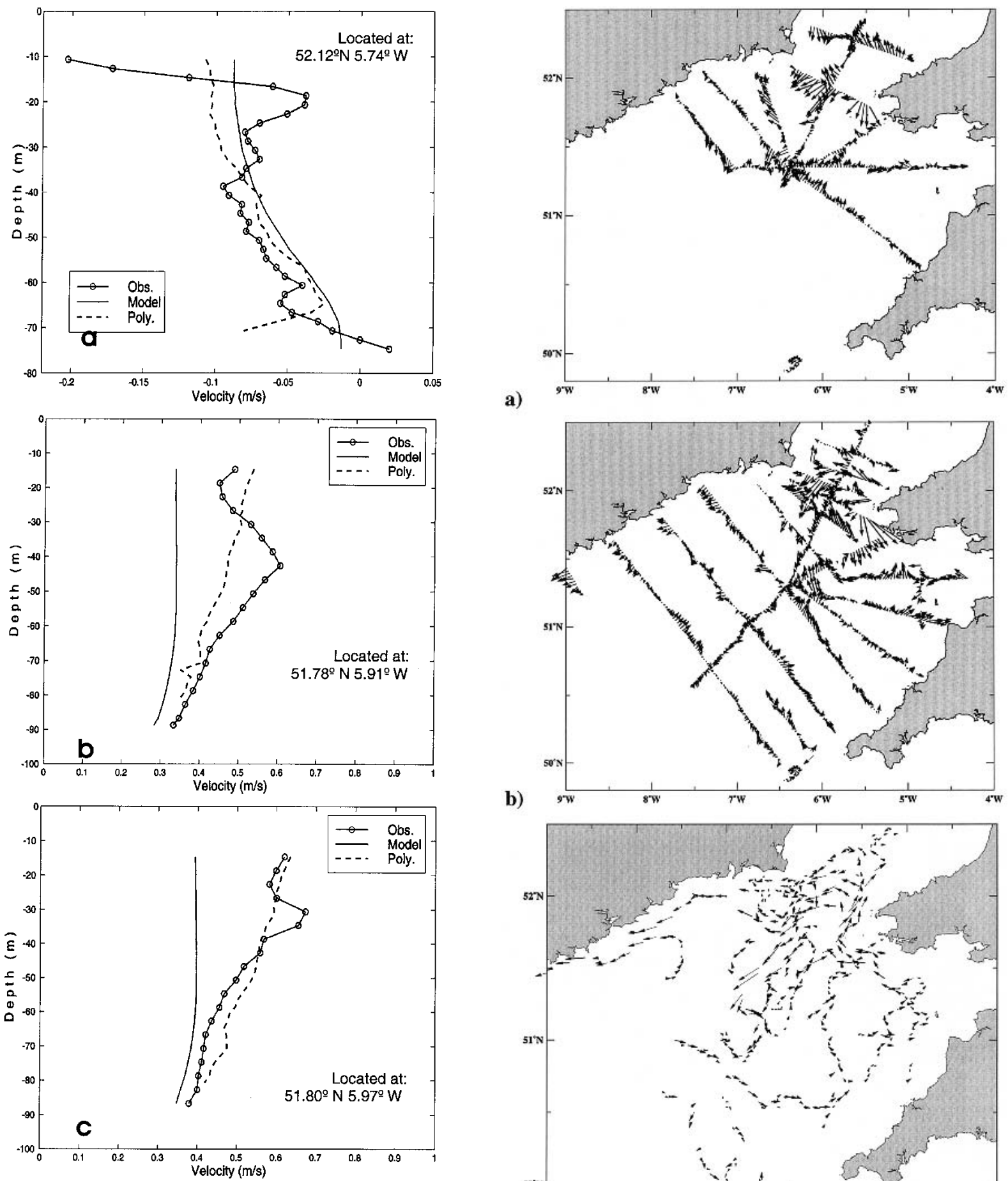

b)

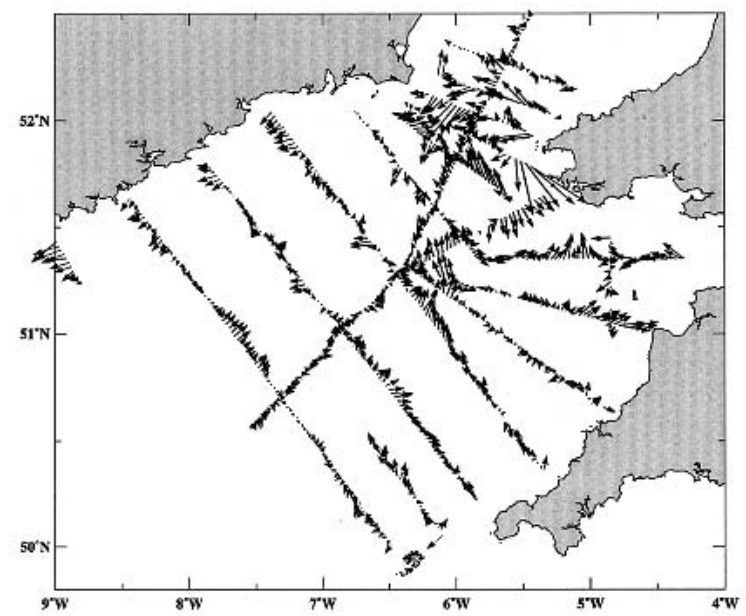

FIG. 8. Examples of vertical current profiles ( $v$ component $)$ at three different locations (see Fig. 2b): ADCP observations contended tidal and subtidal currents (circles and solid line), predicted barotropic tidal current from numerical model (solid line), and extracted tidal current using least squares method (dashed line).

drifter velocities (Fig. 9c). The residual velocity components were then assigned to a grid of $\sim 4 \mathrm{~km}\left(1 / 28^{\circ}\right.$ latitude by $1 / 28^{\circ}$ longitude) and averaged. Further details of the released drifters and the velocity field are

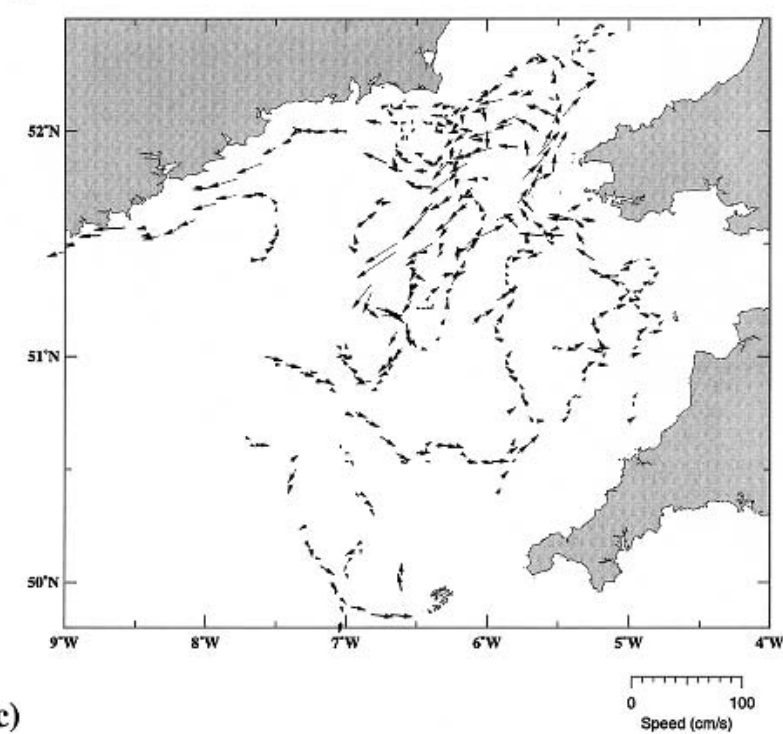

FIG. 9. Subtidal velocities at 30-m depth obtained applying the blending technique. (a) CORY798, (b) CORY998, and (c) pseudo-Eulerian field at 30-m depth obtained from drifter velocities averaged in $1 / 28^{\circ}$ lat $\times 1 / 28^{\circ}$ lon boxes. Scale is displayed in the bottom right. 
described in Brown et al. (2003) and Carrillo (2002). ADCP subtidal currents at 30-m depth (Figs. 9a and 9b) were obtained after applying the detiding blending procedure. Both campaigns showed a complex pattern in the whole area. In general, the residual field showed a nearly cyclonic circulation in the Celtic Sea, with the strongest velocities concentrated in the area of St. George's Channel, particularly near St. David's Head. In the Bristol Channel area, subtidal velocities were noisy and irregular; however, a westward flow in the northern Bristol Channel entrance and an eastward flow at the southern side of the channel entrance can be identified. The quasi-Eulerian field (Fig. 9c) also showed a surface circulation in the Celtic Sea with a variety of spatial structures such as eddies, jets, preferred paths, and convergence zones. In spite of this complexity, they primarily revealed a cyclonic circulation (Brown et al. 2003). Although some differences between the two fields (ADCP residuals and quasiEulerian velocities) were observed, the overall ADCP residual velocity field was qualitatively consistent with the quasi-Eulerian velocity field extracted from the drifters (Fig. 9c).

According to the results obtained by Brown et al. (2003) and Carrillo (2002), strong velocities are expected above the bottom fronts in the Celtic Sea. Thus, strong residual velocities are expected. This can be clearly observed in Fig. 10a, which shows the vertical structure of the subtidal currents derived from the blending method for a cross section in the central St. George's Channel, where bottom frontal structures were observed (Fig. 10b). Subtidal residual currents represent normal velocities to the section (Fig. 10a). Additionally, the geostrophic velocities (Fig. 10c) derived from the density field are shown. Solid contours represent water going into the page, dashed contours represent water out the page. Here we concentrated in flows $>0.05 \mathrm{~m} \mathrm{~s}^{-1}$. Observed residuals and geostrophic velocities were remarkably similar, showing the same order of magnitude and nearly the same position (Figs. 10a and 10c). Jetlike flows $20 \mathrm{~km}$ wide with a core of maximum velocity (up to $0.30 \mathrm{~m} \mathrm{~s}^{-1}$ ) concentrated at approximately $20-40-\mathrm{m}$ depth above the pycnocline (Fig. 10b) were clearly observed in the section (Figs. $10 \mathrm{a}$ and 10c). In addition, drifters that passed through the section are indicated (Fig. 10b). Even when the section was not contemporaneous with the crossing of the drifters, it is remarkable how they agree with the position of the core of jets derived by ADCP residuals.

There were some other areas where the ADCP residuals were strong, such as the shallow region near St. David's Head and the Bristol Channel (Figs. 9a and 9b). Around St. David's Head, tidal currents are particularly strong and the phase of the tidal currents changes considerably. Unfortunately, geostrophic velocities did not show strong density-driven currents because a vertically mixed water column was observed (Carrillo 2002). In addition, it was not possible to com- pare these residual velocities with other measurements because drifters grounded in this region. These strong residuals must be considered with some reserve; because the model was coarse in order to take into account the complexity of the coastal and bathymetric changes and the case of the least squares method, the shape of this coastal area makes the estimation of the tidal currents difficult. Therefore, using the blending technique is expected to result in poor improvement of the tidal estimation.

\section{Discussion}

In this paper, two conventional techniques that detide ship-mounted ADCP data were applied and compared in the shelf area of the Celtic Sea. These respectively involved (a) use of a numerical model from POL and (b) a direct fit to the data using least squares and polynomial spatial interpolation as proposed by Candela et al. (1992). Additionally, an alternative approach to remove the tidal signal from ship-mounted ADCP data was explored, namely, the blending technique.

The least squares detiding technique has not been applied previously in the European shelf seas. While imperfect, the least squares method seems to resolve relatively well the tidal currents. Moreover, the method was able to produce an overall tidal current field similar to that of the numerical model (both methods were approximately the same order). It is important to consider some limitations of this method due to the simplicity of the functions used. The study area was a semienclosed sea with areas of strong tidal currents and rapid phase changes, however, with considerable subtidal currents [up to $40 \mathrm{~cm} \mathrm{~s}^{-1}$ (from Brown et al. 2003; Carrillo 2002)]. It was found that the incorporation of zero velocity along the coast improves the estimate of the tidal currents near the coast using the least squares detiding technique, which was not attempted before. However, further investigation is required to produce optimal functions to account for the spatial variability of the tidal currents and the normal modes of the tidal wave in shelf sea areas. Nevertheless, it is encouraging to note that the least squares method performed reasonably well in extracting the tidal signal from shipmounted ADCP data with considerable tidal signal ( $\sim 90 \%$ of the kinetic energy). In particular, this is potentially important in shelf areas, where assessing the accuracy of a numerical model is not possible and a sparse set of recording current meter data are the only current observations available.

On the other hand, although using a numerical tidal model is one of the most dynamically based approaches for detiding ship-mounted ADCP data, this detiding technique is restricted to regions where the observed tidal currents are well simulated by an existing numerical model. In the European continental shelf sea areas, 
a)

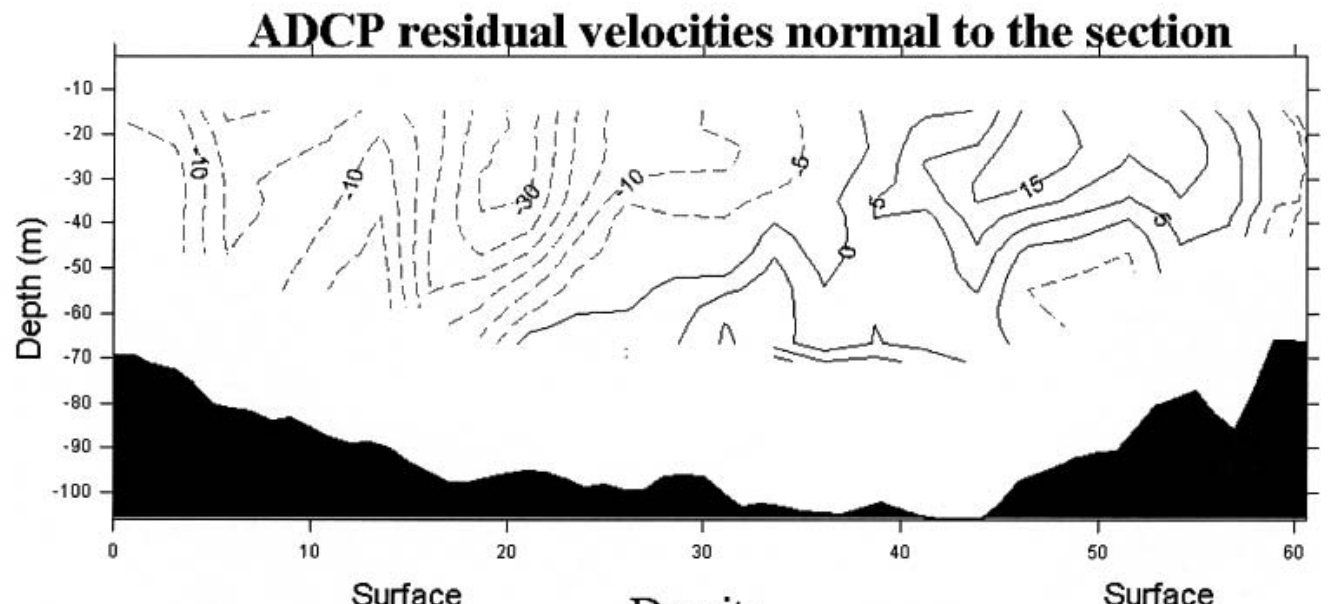

b)

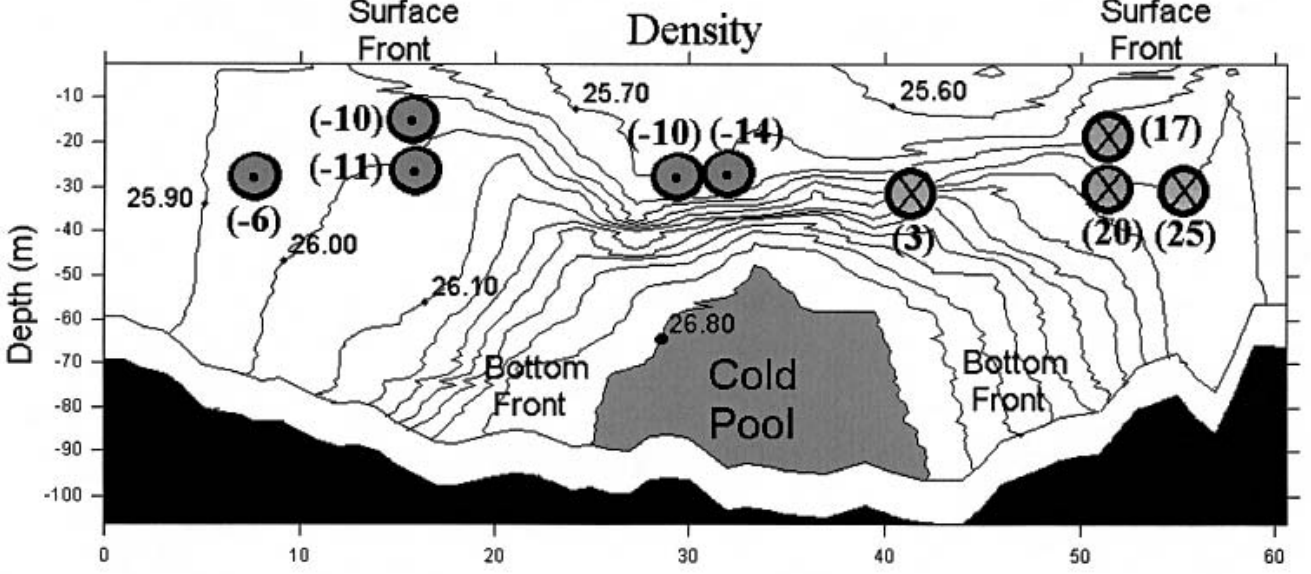

c)

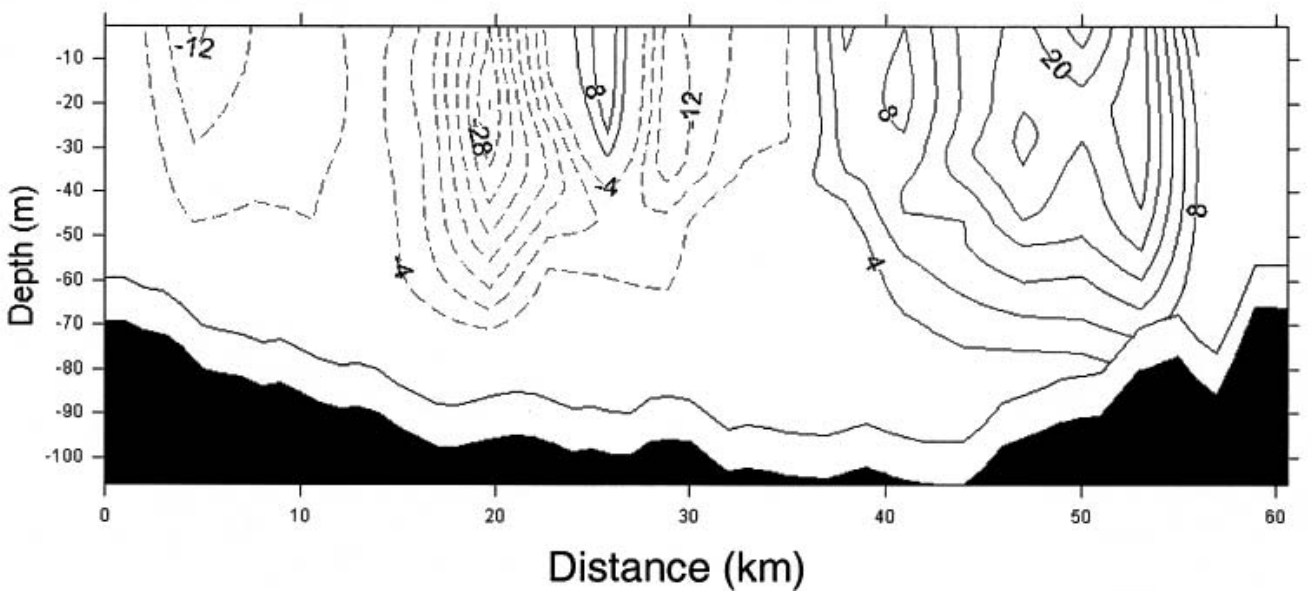

FIG. 10. Cross section at Saint George's Channel; location shown in top-right corner. (a) ADCP residuals normal to the section, (b) vertical structure of density $\left(\sigma_{t}\right)$ in $\mathrm{kg} \mathrm{m}^{-3}$, and (c) geostrophic velocities. (All velocities in $\mathrm{cm} \mathrm{s}^{-1}$.) Drifters crossing the section (denoted by the symbols $\otimes$ and $\odot$, into and out the page, respectively). Number in parentheses represents the drifter velocity normal to the section. 
the well-developed suite of numerical tidal models is an advantage. Clearly, the most significant problems with the dynamical model approximation were the poor resolution and the necessity of correction in order to assess the local variability of the tidal currents. There are a number of potential approaches to correct the numerical model, such as using current meters in an area (Foreman and Freeland 1991); however, the spatial gradients of the tidal currents can be large and some inaccuracies might be expected in this correction. Better improvements can be expected by combining the ship-mounted ADCP data and the numerical model. Howarth and Proctor (1992) corrected the phase shift of the model applied in the North Sea by using an ADCP dataset, concluding that ship-mounted ADCP measurements provide a spatial and temporal check on the model predictions. In the present study, the alternative correction to the numerical model involved the use of the detiding blending technique, which resembles the linear combination of data and dynamics used in data assimilation. To assess the improvement resulting from the blending procedure, we have compared the nontidal residuals with the velocity field from contemporaneous satellite-tracked drifters released in the study area, showing that the overall horizontal ADCP residual circulation was qualitatively consistent with the flow field portrayed by the drifters.

To extend the detiding to a three-dimensional space requires inclusion of the vertical structure of tidal currents, which, for instance, is influenced by bottom friction, which causes tidal currents to change earlier near the bottom than near the surface (Prandle 1982; Mass and van Haren 1987). In the numerical model approach a theoretical analytical profile based on boundary layer theory (Prandle 1982) was used. However, representation of the vertical structure of tidal currents in stratified water column needs to be considered in further research, so that the use of a three-dimensional baroclinic fine-resolution model should be the next natural step. It is important to consider that most of the measurements were performed in stratified water columns and a decoupling of the tidal currents associated with a reduction in the eddy viscosity in the pycnocline (Mass and van Haren 1987; Visser et al. 1994; Souza and Simpson 1996). This can cause abrupt changes in tidal phases across the pycnocline, which was not considered in the analytical profile of Prandle (1982). The tidal profiles obtained with Prandle's theoretical approach presented a smoother curve shape than with the least squares. A better approximation to the profile was obtained with the latter method. Although, from Fig. 8, it can be seen that the main contribution to the magnitude of the velocities on the profile was the tidal barotropic profile; however, the vertical structure of the measured currents showed high variability. Dissimilarities with the barotropic tidal profile could also represent the subtidal currents, which in all the cases were stronger and more variable in the top $40 \mathrm{~m}$, above the pycnocline. This can be expected since the surface water column is more susceptible to the influence of other forcing, such as wind and density gradients. The idea supporting the blending analysis is simply to compute weighted profiles using the results from both methods. A way to optimize these weights could be to use the variance values from current meter observations; however, these data are not available for most of the regions and they are expected to vary spatially. Despite the simplicity of this approach, it was particularly effective in removing the vertical tidal current profile from the measured ADCP to reveal relatively strong jetlike flows in regions with strong horizontal density gradients, as expected from geostrophy and, recently, drifters' releases in this area (Brown et al. 2003; Carrillo 2002).

Ship-mounted ADCP measurements are routinely obtained in most of the oceanographic surveys and often finish stored in a databank because of the unreliability of the detiding techniques. Neither detiding technique extracts the real tidal current field. However, in this paper, we have shown that a combination of tidal currents from both the numerical dynamical model and the ADCP data will prove potentially valuable in detiding tidal currents from ship-mounted ADCP measurements in shelf areas. It would be an interesting future avenue for research to explore a more statistical blending scheme (i.e., by using weights in function of the space or instead of using polynomial functions, it could be interesting to introduce optimal interpolation functions) for tidal estimations in shelf sea areas.

Acknowledgments. CEFAS staff were funded by the Ministry of Agriculture Fisheries and Food. AEH was partly funded by U.K. Natural Environmental Research Council Award GR3/9601; LC's studentship was funded by CONACyT (Mexico). We are thankful for the support provided by the officers and crew of the $\mathrm{R} / \mathrm{V}$ Corystes. We also thank POL (in particular, Dr. J. E. Jones) for allowing the use of the tidal harmonics.

\section{REFERENCES}

Brown, J., L. Carrillo, L. Fernand, K. J. Horsburgh, A. E. Hill, E. F. Young, and K. J. Medler, 2003: Observations of the physical structure and seasonal jet-like circulation of the Celtic Sea and St. George's Channel of the Irish Sea. Cont. Shelf Res., 23, 533-561.

Candela, J., R. C. Beardsley, and R. Limeburner, 1992: Separation of tidal and subtidal currents in ship-mounted acoustic Doppler current profiler observations. J. Geophys. Res., 97, 769788.

Carrillo, L., 2002: Observations of cold pool jets in the continental shelf of the Celtic Sea. Ph.D. thesis, University of Wales, Bangor, United Kingdom, 249 pp.

Davies, A. M., and J. E. Jones, 1992: A three dimensional model of the M2, S2, N2, K1 and O1 tides in the Celtic Sea and Irish Seas. Progress in Oceanography, Vol. 29, Pergamon, 197-234.

Foreman, M. G. G., and H. J. Freeland, 1991: A comparison of techniques for tide removal from ship-mounted acoustic Doppler measurements along the southwest coast of Vancouver Island. J. Geophys. Res., 96, 17 007-17 021. 
Howarth, M. J., and R. Proctor, 1992: Ship ADCP measurements and tidal models of the North Sea. Cont. Shelf Res., 12, 601623.

Joyce, T. M., 1989: On situ "calibration" of shipboard ADCPs. $J$. Atmos. Oceanic Technol., 6, 169-172.

Kasai, A., T. P. Rippeth, and J. Simpson, 1999: Density and flow structure in the Clyde Sea front. Cont. Shelf Res., 19, 18331848.

Lermusiaux, P. F. J., 1997: Error subspace data assimilation methods for ocean field estimation: Theory, validation and application. Ph.D. thesis, Harvard University, 402 pp.

Lwiza, K. M. M., D. G. Bowers, and J. H. Simpson, 1991: Residual and tidal flow at a tidal mixing front in the North Sea. Cont. Shelf Res., 11, 1379-1395.

Mass, L. R. M., and J. J. M. van Haren, 1987: Observations on the vertical structure of tidal and inertial currents in the central North Sea. J. Mar. Res., 45, 293-318.

Münchow, A., 2000: Detiding three-dimensional velocity survey data in coastal waters. J. Atmos. Oceanic Technol., 17, 736749.

- R. W. Garvine, and T. F. Pfeiffer, 1992: Subtidal currents from a shipboard acoustic Doppler current profiler in tidally dominated waters. Cont. Shelf Res., 12, 499-515.

Pingree, R. D., 1980: Physical oceanography of the Celtic Sea and English Channel. Physical and Chemical Oceanography and Physical Resources, F. T. Banner, M. B. Collins, and K. S. Massie, Eds., The North-West European Shelf Seas: The Sea Bed and the Sea in Motion, Elsevier Oceanography Series, Vol. 24B, Elsevier, 415-465.
Prandle, D., 1982: The vertical structure of tidal currents and other oscillatory flows. Cont. Shelf Res., 1, 191-207.

Robinson, A. R., P. F. J. Lermusiaux, and N. Q. Sloan III, 1998: Data assimilation. The Sea, K. H. Brink and A. R. Robinson, Eds., The Global Coastal Ocean, Vol. 10, Wiley and Sons, 541-594.

Robinson, I. S., 1979: The tidal dynamics of the Irish Sea and Celtic Sea. Geophys. J. Roy. Astron. Soc., 56, 159-197.

Simpson, J. H., E. G. Mitchelson-Jacob, and A. E. Hill, 1990: Flow structure in a channel from an acoustic Doppler current profiler. Cont. Shelf Res., 10, 589-603.

Souza, A. J., and J. H. Simpson, 1996: The modification of tidal ellipses by stratification in the Rhine ROFI. Cont. Shelf Res., 16, 997-1007.

Steger, J. M., C. A. Collins, F. B. Schwing, M. Noble, N. Garfield, and M. T. Steiner, 1998: An empirical model of the tidal currents in the Gulf of Farallones. Deep-Sea Res., 45B, 14711505.

Valle-Levinson, A., and K. M. M. Lwiza, 1998: On the influence of downwelling winds on the Chesapeake Bay outflow. Physics of Estuaries and Coastal Seas, J. Dronkers and M. B. A. M. Scheffers, Eds., A. A. Balkema, 247-256.

Visser, A. W., A. J. Souza, K. Hessner, and J. H. Simpson, 1994: The effect of stratification on tidal current profiles in a region of freshwater influence. Oceanol. Acta, 17, 369-381.

Wong, K., and A. Münchow, 1995: Buoyancy forced interaction between estuary and inner shelf: Observation. Cont. Shelf Res., 15, 59-88. 